\title{
ANÁLISE DA ARMADURA PASSIVA EM LAJES LISAS DE PROTENSÃO NÃO ADERENTE
}

\author{
Eduardo Felipe Bezerra da Silva \\ Bacharel em Engenharia Civil pelo Centro Federal de Educação Tecnológica Celso \\ Suckow da Fonseca (CEFET-RJ), Rio de Janeiro, RJ, Brasil. \\ seduardob@hotmail.com \\ Marcos Araujo Braz de Oliveira \\ Mestre em Engenharia Civil pela Universidade Federal Fluminense (UFF), Rio de \\ Janeiro, RJ, Brasil. \\ Professor do Departamento de Engenharia Civil do Centro Federal de Educação \\ Tecnológica Celso Suckow da Fonseca (CEFET-RJ), Rio de Janeiro, RJ, Brasil. \\ ma_braz@terra.com.br
}

\section{RESUMO}

O presente estudo busca explanar as possibilidades de dimensionamento das armaduras complementares passivas em estruturas de lajes lisas em concreto protendido com cordoalhas engraxadas e plastificadas pós-tracionadas, onde existe uma direção de cabos distribuída e outra concentrada. Desta forma, tentar trazer uma comparação entre métodos de dimensionamento de tais estruturas. Para chegar as conclusões deste estudo se valeu de revisões bibliográficas e testes em uma estrutura hipotética utilizando um software específico, este emprega o método das grelhas e o método das cargas balanceadas. Por fim será demonstrada a diferença de quantitativos de armadura passiva a depender do método escolhido e será também avaliada a validade da utilização de cada método.

Palavras-chave: Protendido. Passiva. Engraxada. Plastificada. Pós-tracionada.

\section{REVIEW PASSIVE REINFORCEMENTS ON FLATS SLABS OF UNBONDED POST- TENSIONED TENDON}

\begin{abstract}
The present study seeks to explain possibilities of dimensioning the passive complementary armor in structures of flat slabs in prestressed concrete with greased and plastified post-tensioned cables slabs where there is a distributed direction of cables and a concentrate direction of cables. In this way, try to bring a comparation between methods of designing such structures. To spell out at conclusions of this study, was used bibliographical reviews and tests in a hypothetical structure using a specific software,
\end{abstract}


this software uses the grid method and the balanced load method. Finally it is shown a quantitative difference passive armor depending on the method chosen, and will also evaluated the validity of the use of each method.

Keywords: Prestressed. Passive. Greased. Plastified. Post-tension.

\section{INTRODUÇÃO}

As lajes lisas em concreto protendido com protensão não aderente permitem projetos arquitetônicos onde grandes vãos devem ser vencidos; podem auxiliar no atendimento normativo quando pequenas deformações são toleradas; permitem um acréscimo do número de pavimentos de um empreendimento, pois admitem a execução com um menor pé-direito; e, por vezes, torna projetos tecnicamente possíveis, por exemplo, quando as fundações não tenham capacidade de receber grandes carregamentos.

Os principais objetivos deste estudo são:

i. Apresentar dois métodos de dimensionamento das armaduras passivas;

ii. Detalhar e dimensionar uma estrutura hipotética simplificada, em concreto protendido (por dois métodos de dimensionamento de armaduras passivas);

iii. Incentivar a discussão acadêmica para aprimoramento dos métodos utilizados; e

iv. Comparar métodos de dimensionamento abordados

Para lajes lisas em concreto protendido existem algumas lacunas que merecem ser discutidas e não são abordadas com grande clareza na norma brasileira (NBR 6118 - 2014), nem possuem grande debate na literatura acadêmica, apesar de sua relevante aplicabilidade.

\section{CONCEITOS BÁSICOS}

\subsection{Métodos de cálculo de esforços}

Usar-se-á, neste estudo, o conceito de faixas de projeto, doravante chamadas de RTE ? Região de Transferência de Esforços, nomenclatura derivada da norma americana 
(ACl 318-08) e também no programa utilizado para o estudo de caso (TQS). Esse conceito é empregado para os métodos de pórticos equivalentes e adaptado para o método das grelhas, utilizado neste estudo.

\subsubsection{Faixas de projeto - RTE}

As faixas de projeto associam-se à delimitação do caminho que as cargas farão até os apoios, as quais existem na direção transversal e na longitudinal. Chama-se de linha de apoio a união dos segmentos que ligam os pilares aproximadamente alinhados em uma mesmo direção. Cada linha de apoio é associada a uma faixa. (LOUREIRO, 2006).

Após a definição da linha de apoio (ver Figura 1 à Figura 3), limita-se lateralmente a faixa tributária com as linhas que unem os pontos médios adjacentes à duas linhas de apoio ou por uma face externa da laje (ver Figura 4), estes serão os limites das RTEs (ver Figura 5 e Figura 6). Nestas RTEs são selecionadas seções de projeto onde são feitas as análises (ver Figura 7). Avaliando os esforços cortantes pelo método dos elementos finitos, nota-se a semelhança entre as delimitações das RTE e as linhas de cortante nulo (Figura 8). Essa comparação é válida quando o alinhamento dos pilares está aproximadamente uniforme. (FARIA, 2004).

Figura 1 - Forma de referência Figura 2 - Linhas de Apoio na direção x Figura 3 - Linhas de Apoio na direção y
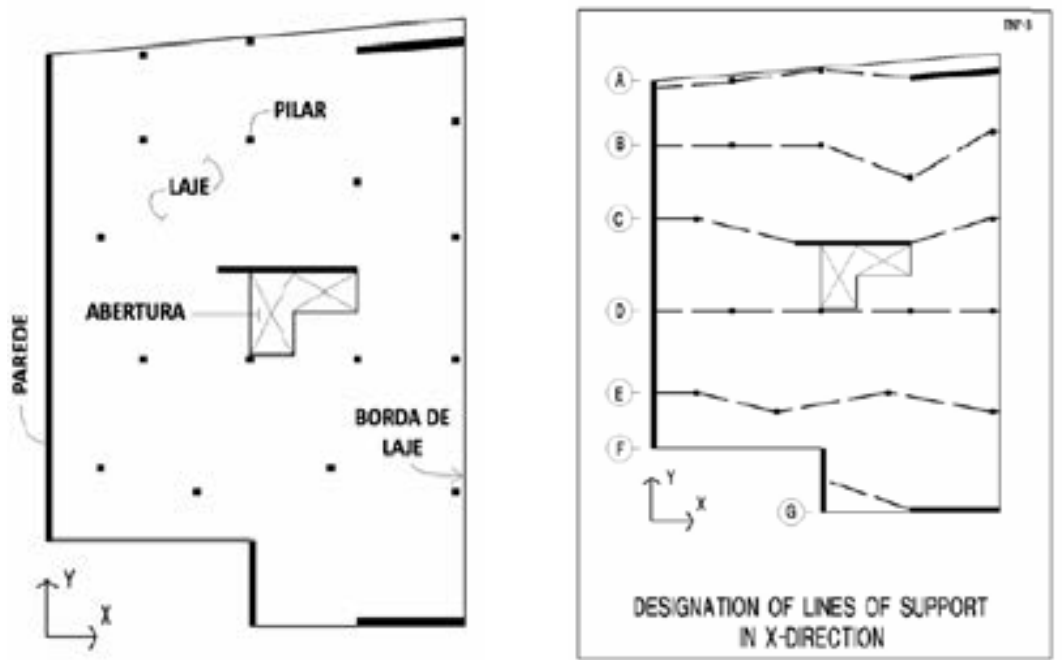


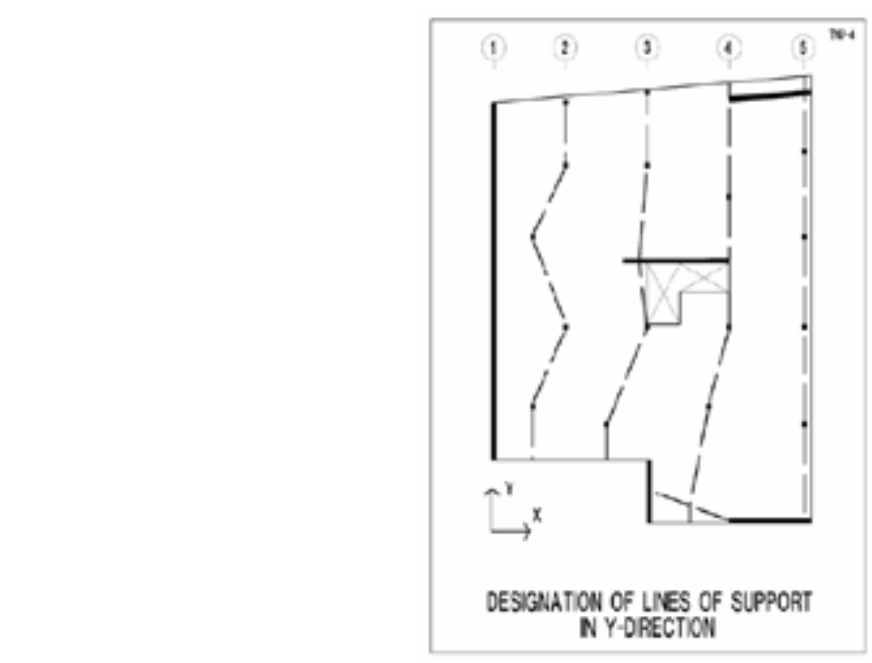

Fonte: LOUREIRO (2006)

Fonte: LOUREIRO (2006

Fonte:

LOUREIRO (2006)

Figura 4 - Marcação dos pontos médios direção y

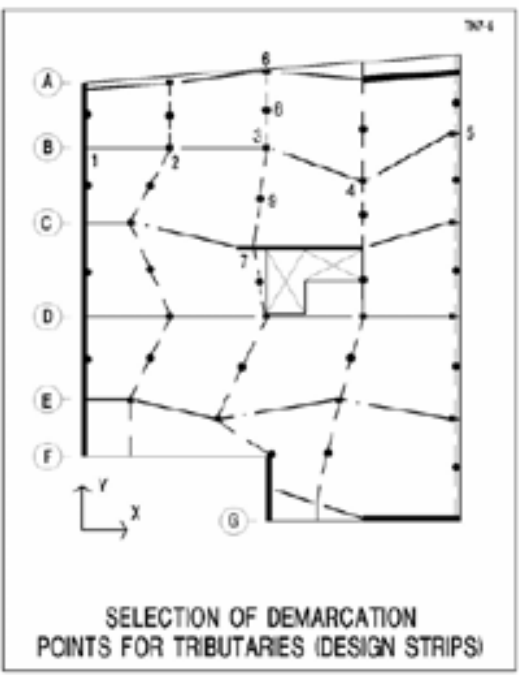

Figura 5 - RTE: direção $x$

Figura 6 - RTE:

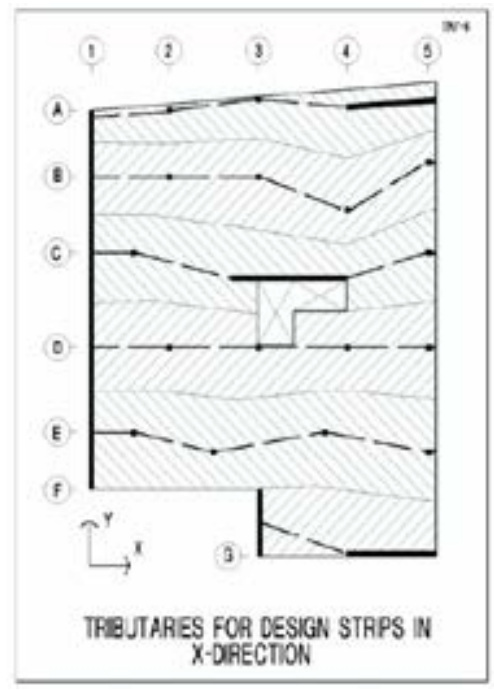




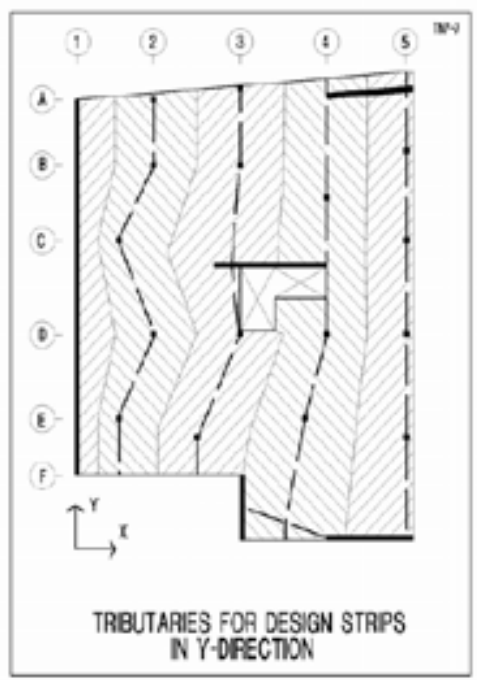

Fonte: LOUREIRO (2006)

Fonte: LOUREIRO (2006) (2006)

Fonte: LOUREIRO 
Figura 7 - Seções de projeto

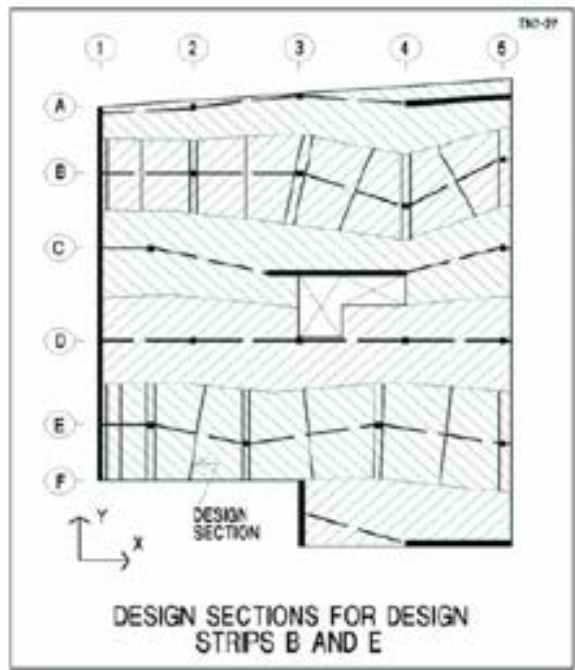

Fonte: LOUREIRO (2006)
Figura 8 - Cortante por elementos

finitos e RTE

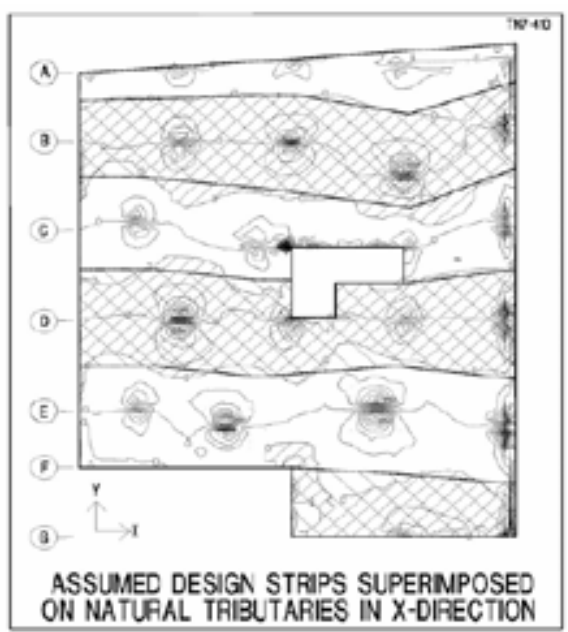

Fonte: LOUREIRO (2006)

\subsubsection{Métodos das grelhas}

Mello, 2005, observa que este método adequa-se bem as mais diversas geometrias, sendo possível levar em consideração aberturas por ventura existentes. É apropriado, para esse método, a protensão ser inserida como carga equivalente, conforme método apontado posteriormente. Mello (2005 apud Timoshenko e Woinowsky, 1959) aborda ainda que Marcus introduziu o conceito de grelha equivalente em substituição a laje como uma placa.

Faria 2004 explica que por este método se discretiza a laje em uma grelha para obtenção dos momentos fletores e esforços cortantes. A laje será dividida em RTEs e em faixas de distribuição onde os cabos serão lançados, faixas estas que doravante serão chamadas de RPUs ? Região de Protensão Uniforme (nomenclatura utilizada no TQS). Cada RTE é considerada isoladamente e pode ter o momento de dimensionamento definido como: a média ponderada dos momentos de cada seção ou pelo momento máximo das barras que atravessam a seção.

A rigidez à torção e à flexão são concentradas nos elementos (barras) das grelhas. Além disso, a deformabilidade e torção das vigas periféricas, bordas com rotação impedida parcialmente e ausência de vigas podem ser consideradas no cálculo. Para as barras da laje a inércia a flexão é considerada somando-se metade dos espaços vazios vizinhos e a altura da laje. (MELLO, 2005). 


\subsubsection{Métodos das cargas equivalentes}

T.Y. Lin, em 1963, introduziu o conceito do método das Cargas Balanceadas ou Equilibrantes (Load Balancing). Para Emerick (2005), o método é um dos mais adequados para o cálculo de lajes protendidas, baseando-se no princípio de fazer com que, para certo carregamento, a estrutura, através do traçado e elevação dos cabos, equilibre uma parcela do carregamento. Faria (2004) explica o mesmo, porém acrescenta que o método busca equilibrar as cargas verticais e a estrutura deve submeter-se somente a tensões uniformes de compressão devido à força normal de protensão e, além disso, não apresente flechas.

Segundo Loureiro, 2006, neste método a protensão é tratada como um carregamento externo. Desta forma, apenas o carregamento vertical da protensão é considerado, a parcela horizontal da força de protensão é utilizada apenas nas verificações de tensões.

\subsection{Armaduras passivas}

O cerne do presente projeto encontra-se no cálculo das armaduras passivas. É importante informar, que o aspecto mais relevante para a seguinte análise será a largura da faixa de influência da protensão considerada em projeto. Então, os cálculos que possuem elementos com taxa de armadura ativa são fortemente influenciados, dependendo do método escolhido, pois quanto menor a faixa de influência considerada, maior será a taxa de armadura ativa.

Para o método das grelhas, tem-se um tratamento pouco abordado na literatura técnica, porém aplicado na prática comercial, este é a relação entre a região de tratamento da laje (RTE) e a região de projeção dos cabos (RPU), no que se refere à preocupação com a distribuição da armadura passiva. Tendo este aspecto em mente existem duas metodologias a serem abordadas: Método de distribuição Tributárias Ampliadas (MTA) e Método de distribuição Tributária Concentrada (MTC), podendo haver outras nomenclaturas (SGARBI, 2015). Esses métodos serão abordados após a demonstração das armaduras mínimas e para atendimento ao ELU.

\subsubsection{Armaduras mínima positiva}


A ABNT NBR 6118 - item 19.3.3.2 (2014), determina que a armadura mínima positiva distribuída por toda a laje (sempre respeitando o limite mínimo de 0,15\%). Mello, 2005, enfatiza a possibilidade de se considerar a armadura passiva mínima funcionando junto com a ativa, conforme visto na verificação do ELU para esforços normais. É ressaltado que esta consideração é compatível com a protensão parcial (utilizada nos estudos de caso). Para a protensão limitada, em geral, a armadura ativa é dimensionada em serviço para combinação quase permanente (só a armadura ativa altera o estado de tensões).

2.2.2 Armaduras mínima negativa

Definida pela ABNT NBR 6118 - itens 19.3.3.2 e 20.3.2.6 (2014), sobre apoios.

\subsubsection{Armaduras complementar para atendimento ao ELU}

Usa-se na verificação de ELU (Equação 1): $\frac{M_{d}}{K_{z} d}=\frac{\sigma_{p u} A_{p}}{1,15}+F_{y d} A_{s}$

Para altas solicitações a parcela da protensão é insuficiente (Equação2):

$$
\frac{M_{d}}{K_{z} d}-\frac{\sigma_{p u} A_{p}}{1,15} \leq 0
$$

Daí verifica-se se a armadura mínima é suficiente para suprir a solicitação, tendo assim duas possibilidades:

i. A armadura mínima é suficiente (Equação 3): $\frac{M_{d}}{K_{z} \mathrm{~d}}-\frac{\sigma_{p u} A_{p}}{1,15} \leq F_{y d} A_{s, \min }$ Para este caso não são necessárias outras análises.

ii. A armadura mínima é insuficiente (Equação 4): $\frac{M_{d}}{K_{z} \mathrm{~d}}-\frac{\sigma_{p u} A_{p}}{1,15}>F_{y d} \cdot A_{s, \min }$
iii. Calcula-se então a armadura necessária pela equação (Equação 5):

$\frac{M_{d}}{K_{z} \mathrm{~d}}-\frac{\sigma_{p u} A_{p}}{1,15}=F_{y d} \cdot A_{s}$

Se a região analisada for de esforço negativo, utiliza-se a $A_{s}$ encontrada. Porém, se a região for de esforço positivo, utiliza-se uma armadura complementar $\left(A_{s, \text { comp }}\right)$ à armadura mínima (Equação 6):

$$
A_{s, \text { comp }}=A_{s}-A_{s, \min }
$$

2.3 Metodologias de distribuição 
2.3.1 Metodologia de distribuição tributária concentrada

Nessa metodologia, a largura da faixa de cálculo de esforços (RTE) é igual a largura da faixa de projeção dos cabos (RPU). Segundo Sgarbi, 2015, os seguintes aspectos são observados por esta metodologia: (i) Consideração efetiva dos esforços normais induzidos nas ancoragens; (ii) As forças verticais dos cabos são consideradas em suas respectivas projeções; (iii) Dimensionamento das regiões de acordo com a configuração de esforços e considerando ou não a presença de cabos.

É muito comum considerar uma direção com protensão distribuída ao longo de toda a laje (distribuição uniforme) e a outra com faixas concentradas (distribuição concentrada). Para a distribuição uniforme as RTEs possuem mesmo tamanho das RPUs, já na distribuição concentrada tem-se diferentes regiões, algumas com concentração de protensão e outras com protensão inexistente, calculadas estas, em princípio, como concreto armado convencional. Considere as três regiões existentes (Figura 9 e Figura 10):

- Região A: submetida a cargas verticais e esforços de compressão;

- Região B: submetida diretamente apenas aos esforços normais;

- Região C: sem efeito da protensão na direção considerada. 
Figura 9 - RPUs e RTEs

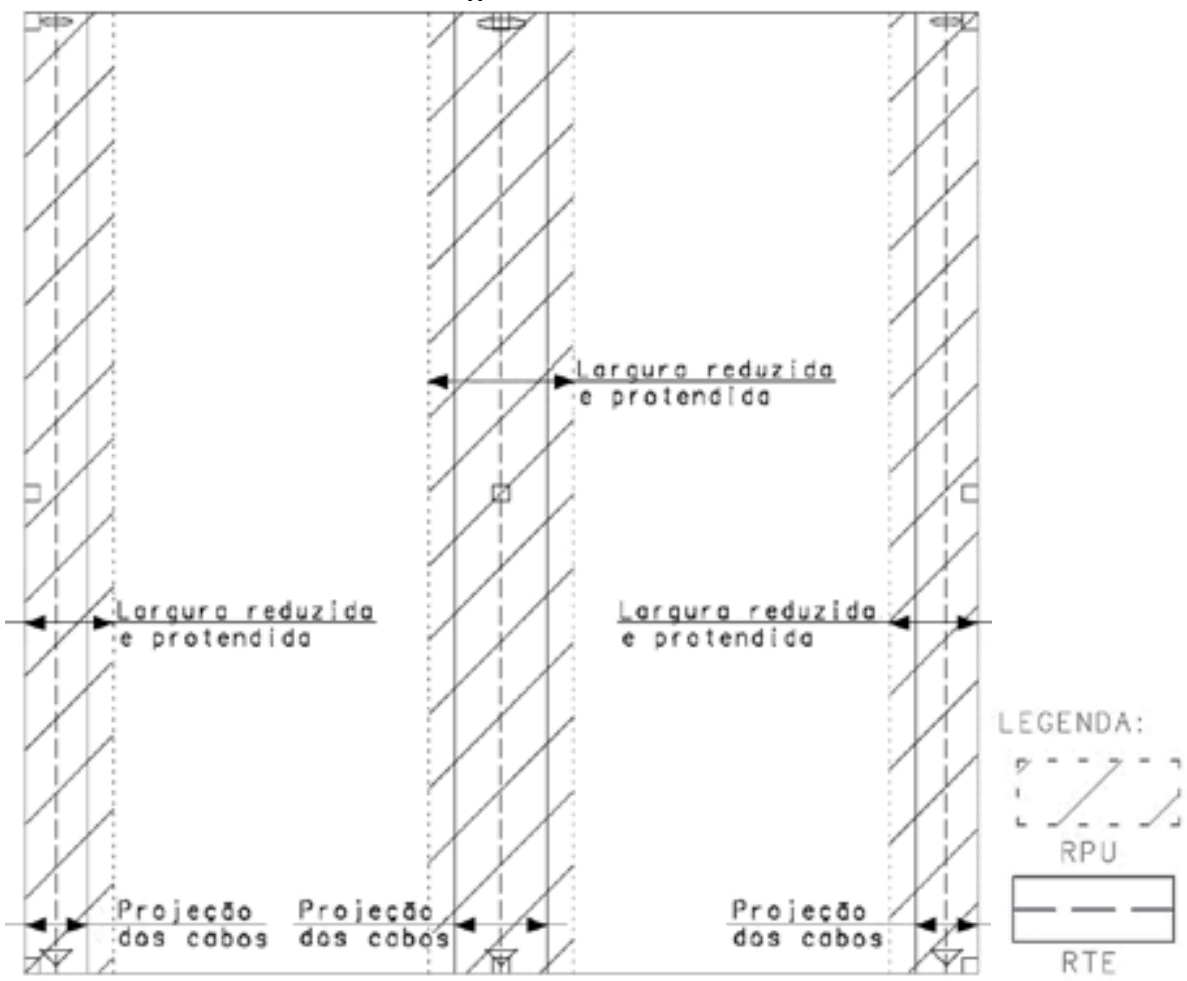

Fonte: Próprio autor, 2016

Figura 10 - Regiões de esforços

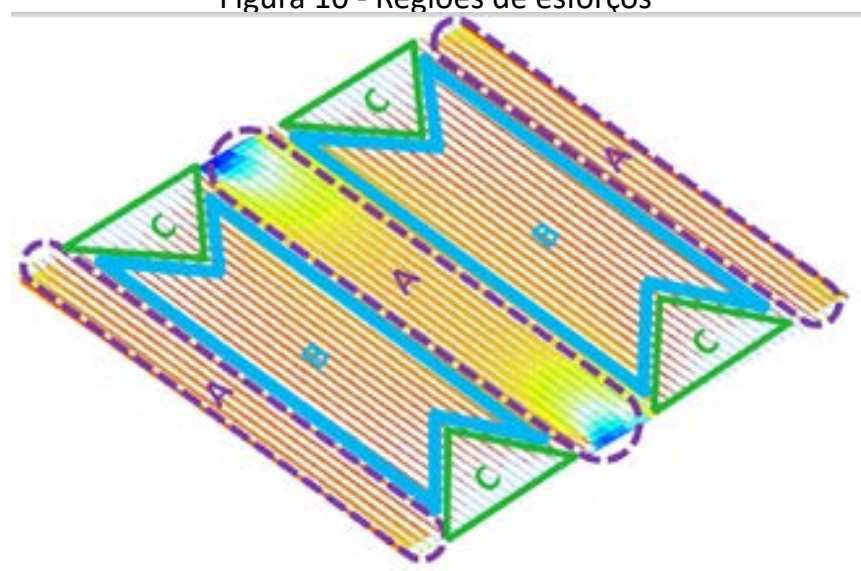

Fonte: Próprio autor, 2016

2.3.2 Metodologia de distribuição tributária ampliada

A diferença entre este método e o das tributárias concentradas, consiste na discretização das regiões. Neste caso a RTE é, de forma análoga, a faixa utilizada no 
método dos pórticos equivalentes. Porém, em vez da linha média entre os apoios, utilizase as linhas obtidas dos alinhamentos de cortantes nulos e, neste caso apropriandose dos conceitos de elementos finitos, considerando a influência das duas direções protendidas, enquanto o método dos pórticos equivalentes faz uma análise linear. Os esforços para cada verificação são obtidos da integração dos esforços que compõem toda a seção da faixa. (SGARBI, 2015).

Sgarbi, 2015, aponta quatro requisitos para que esta metodologia possa ser aplicada:

i. Cabos distribuídos uniformente em uma direção: para garantir a uniformidade dos esforços nas tributárias da outra direção.

ii. Pré-compressão maior que, ou igual, a $1 \mathrm{MPa}$ (conforme) ABNT NBR 6118 - item 20.3.2.1).

iii. Regularidade na distribuição dos pilares para uma mesma tributária. Ou seja, ao longo da seção transversal deve haver certa uniformidade, pois, este método utiliza uma média dos esforços na seção, levando em conta o estado de compressão bidirecional. Havendo irregularidade, a média não representará um valor aceitável para a seção.

iv. Protender primeiramente a direção de cabos distribuídos. A priori imagina-se que é necessário protender a direção concentrada buscando a caracterização das 'pseudovigas'. Entretanto, há a necessidade de regularização dos esforços e de manter-se um estado de tensões na laje. Por isso o pré-alongamento é executado primeiro na direção distribuída. 
Figura 11 - RPUs e RTEs

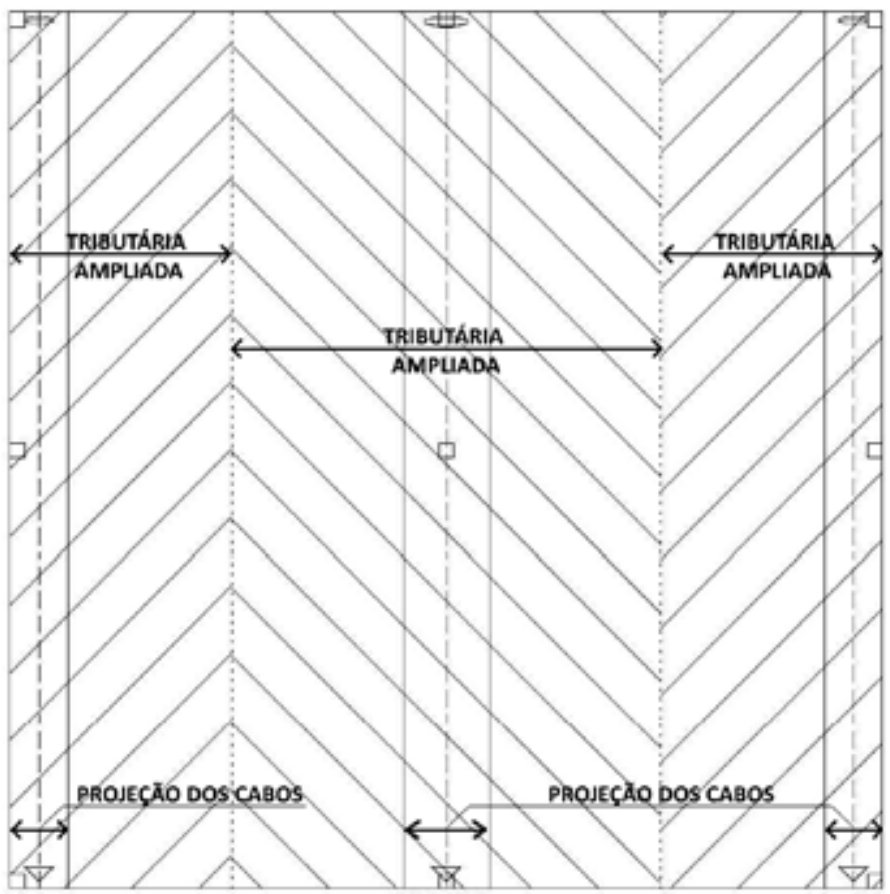

Fonte: Próprio autor, 2016

\subsection{Estudo de caso}

Serão apresentados os dimensionamentos e ao fim será avaliado o consumo de armadura passiva valendo-se dos dois métodos apresentados anteriormente: MTA e MTC.

\subsubsection{Premissas de projeto}

A seguinte estrutura servirá de exemplo para demonstrar as comparações executadas. Trata-se de uma estrutura, de lajes lisas, simétrica, com vãos de 9 metros e altura da laje de $22 \mathrm{~cm}$. A baixa rigidez dos pilares simula bem as situações encontradas nos edifícios residenciais e comerciais. Sua forma pode ser observada na Figura 12.

O pavimento considerado tem as seguintes características:

- Materiais $-\mathrm{F}_{\mathrm{ck}}=35 \mathrm{MPa}$; armadura passiva: CA-50 A; armadura ativa: CP $190 \mathrm{RB}$

$15,2 \mathrm{~mm}$; carga de ruptura mínima das cordoalhas: $265,8 \mathrm{kN}$; seção dos feixes:

$140,0 \mathrm{~mm}^{2} ; \mathrm{F}_{\mathrm{ptk}}=1900 \mathrm{MPa} ; \mathrm{F}_{\mathrm{ctk}, \text { inf }}=3,37 \mathrm{MPa} ; \mathrm{F}_{\mathrm{ctj}}=1,18 \mathrm{MPa}$; 
- Características da protensão - pré-alongamento da armadura ativa: pós-tração; aderência: não aderente, engraxada e plastificada; nível de protensão: Nível 1 , protensão parcial; perdas por atrito: fixadas em 15\%;

- Fissuração e deformação - classificação: CAA II; exigência quanto a fissuração: atender ELS-F para o caso de combinação frequente das ações (conforme nota da Tabela 13.4 da ABNT NBR 6118, que permite apenas essa verificação para lajes lisas protendidas); limite de deformação: Aceitação sensorial visual de $3,6 \mathrm{~cm}$;

- Cargas: permanentes $3 \mathrm{kN} / \mathrm{m}^{2}$ e acidentais $3 \mathrm{kN} / \mathrm{m}^{2}$;

- Combinação a utilizar em serviço: combinação frequente (CF) $1,0 g$ + 1,4q + 1,0p;

- Combinações para ELU - Caso com ponderadores favoráveis: $1,4 g+1,4 q+1,2 p$ Caso com ponderadores desfavoráveis: $1,0 \mathrm{~g}+1,4 \mathrm{q}+$ $0,9 p$;
Acréscimo de tensão (Equação 7 e 8):
$\Delta \sigma_{p}=70+\frac{350}{300 \cdot \rho_{p}}$
$\rho_{p}=\frac{A_{p}}{b_{w} \cdot d_{p}}$

Esse valor depende do comprimento da faixa considerada $\left(b_{w}\right)$ e da armadura ativa nela contida (da Equação 8). Notar que para o método MTA, esse acréscimo será menor devido ao maior comprimento. Encontrado menores tensões, devido a protensão, como consequência, existirá maior probabilidade de necessidade de armaduras complementares passivas.

\subsubsection{Concepção da estrutura}

Na Figura 12 pode-se verificar a estrutura a ser analisada. Conforme executado comumente, será selecionada uma direção para ser tratada com faixas distribuídas de cabos e a outra com concentração de cabos pontualmente. Devido à simetria da estrutura, a escolha da direção distribuída e concentrada é indiferente. Desta forma, a direção horizontal será a distribuída e a vertical será a concentrada. Foram inseridas no modelo estrutural TQS as RPUs que definirão o traçado dos cabos, conforme se verifica na Figura 13 e Figura 14. 


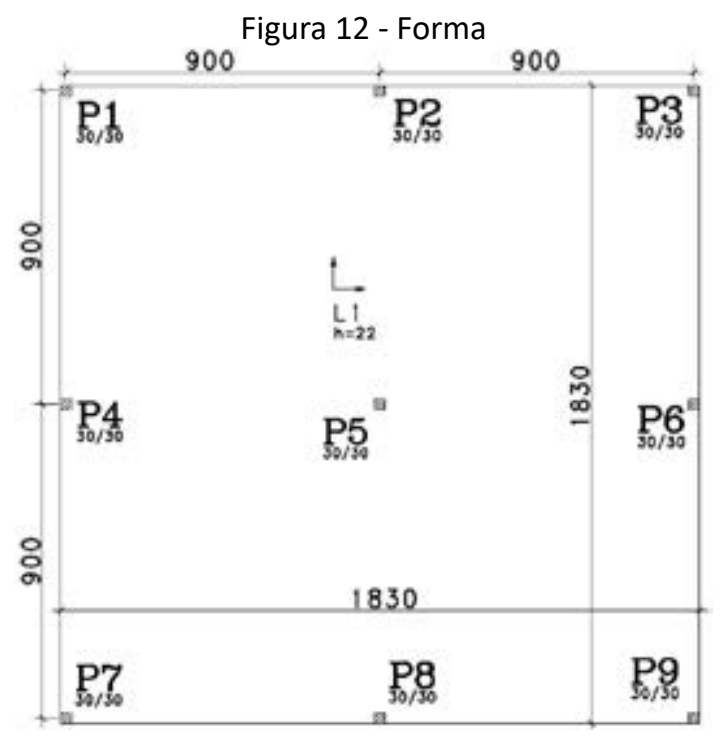

Fonte: SGARBI, 2015

Figura 13 - RPUs na direção dos cabos concentrados

Figura 14 - RPUs na direção dos cabos distribuídos

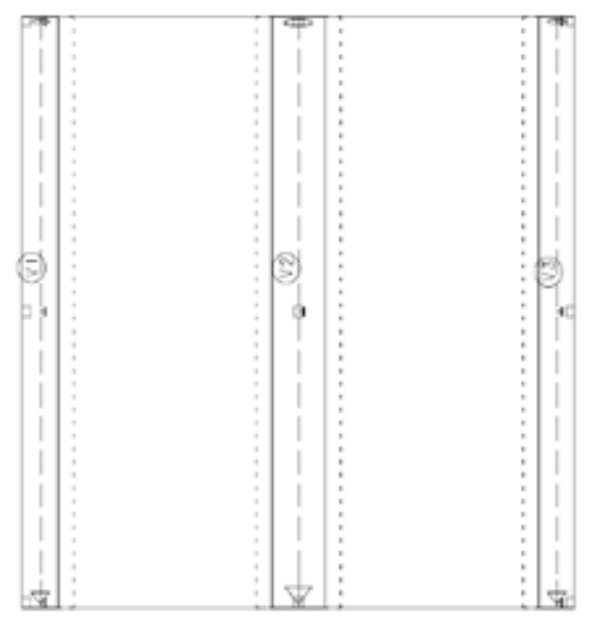

Fonte: Próprio autor, 2016

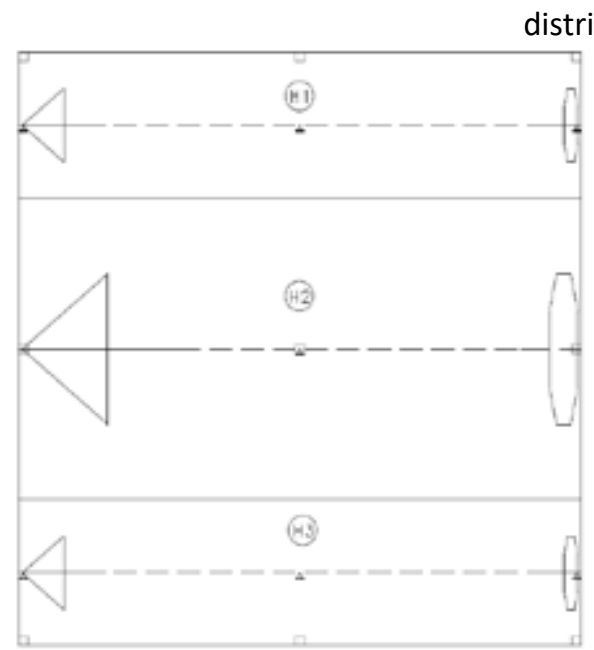

Fonte: Próprio autor, 2016

\subsubsection{Definição das RTEs}

É válido reforçar a necessidade de que a configuração dos cabos gere uma tensão mínima de 1 MPa. Essa prerrogativa da ABNT NBR 6118 (2014) é necessária para que a consideração das RTEs, que configuram a limitação da distribuição dos esforços, sejam coerentes com o mecanismo bidimensional do funcionamento da grelha para concreto protendido.

A seguir serão definidas as RTEs do estudo, entretanto, será demonstrada uma 
divisão representativa para método tributária cabo e outro para o método tributária ampliada.

\subsubsection{Direção dos cabos distribuídos}

Para a direção com cabos distribuídos não se tem diferenciação pelo método tratado, visto que a própria RPU está na efetiva projeção dos esforços dos cabos, assim como das projeções das cargas equivalentes considerada. Sendo assim, a Figura 15 demonstra a coincidência das RPUs e RTEs.

Figura 15 - RTEs na direção distribuída

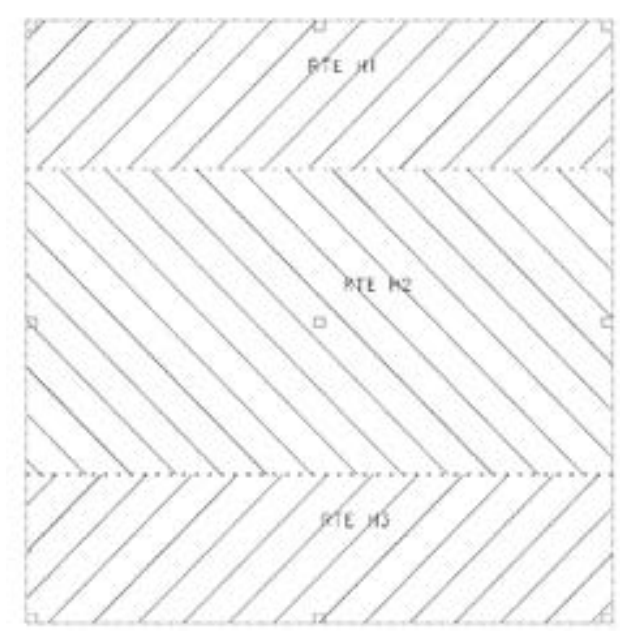

Fonte: Próprio autor, 2016

\subsubsection{Direção dos cabos concentrados pelo MTC}

Conforme já exposto, as RTEs estarão próximas às projeções dos cabos, tem-se então regiões tratadas como concreto armado convencional e outras como concreto protendido. A Figura 16 demonstra a separação das RTEs. Vale notar que as RTEs V2 e V4 devem ser tratadas como concreto armado convencional, ao que se refere a armadura passiva.

\subsubsection{Direção dos cabos concentrados pelo MTA}

A definição das RTEs será baseada no alinhamento dos pilares e separadas aproximadamente no meio dos vãos. Conforme utilizado no método dos pórticos simples 
(e equivalentes), a divisão efetiva faz-se pelos pontos de cortante nulo. A seguir será demonstrada esta divisão na Figura 17.

A estrutura também atende aos requisitos apontados anteriormente em 2.3.2. Figura 16 - RTEs na direção concentrada pelo MTC Figura 17 - RTEs na direção concentrada pelo MTA

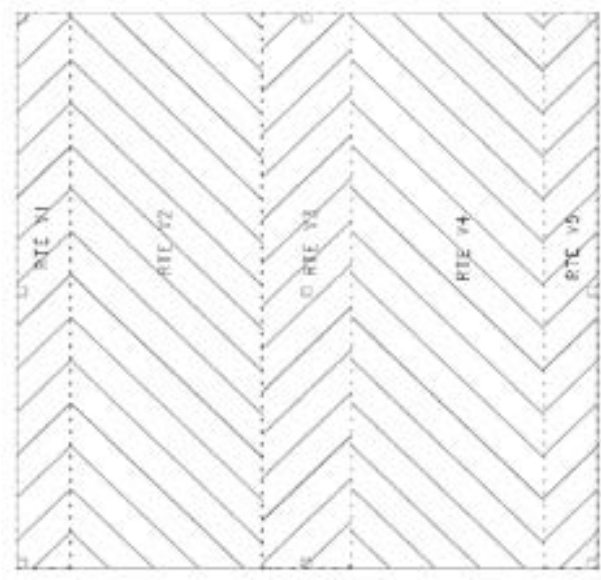

Fonte: Próprio autor, 2016

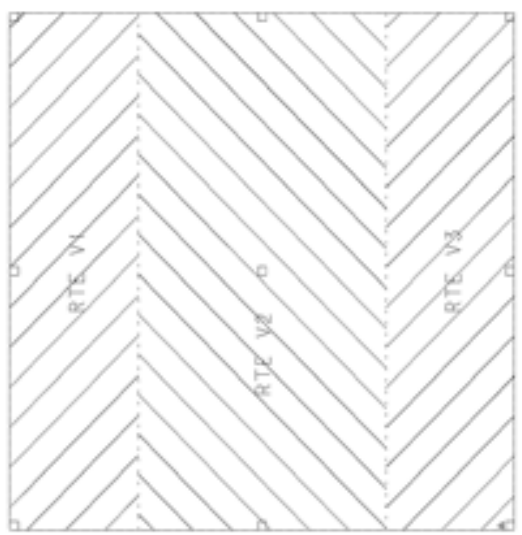

Fonte: Próprio autor, 2016

\subsubsection{Definição dos cabos}

Na Figura 18 são demonstrados os traçados dos cabos e suas quantidades para contemplar as premissas estabelecidas. As configurações dos cabos serão os mesmos tanto para o MTA quanto para o MTC.

Os traçados iniciais sugeridos pelo próprio pelo TQS, após as devidas análises, foram alterados e serão apresentados na Figura 18. 0 total de armadura ativa utilizada para a referida estrutura foi de $2035 \mathrm{~kg}$, totalizando $1659,5 \mathrm{~m}$ de cabos de bitola 15,2 $\mathrm{mm}$. 
Figura 18 - Cabos distribuídos e concentrados

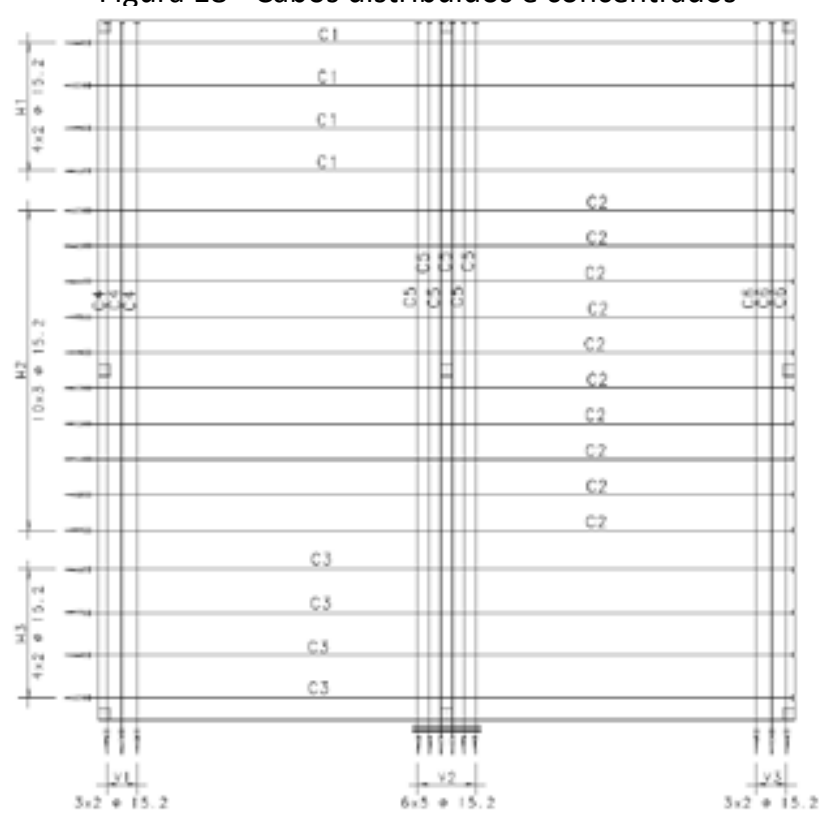

Fonte: Próprio autor, 2016

2.4.5 Armaduras passivas mínimas

Na Tabela 1, têm-se as taxas resumidas:

Tabela 1 - Taxas de armaduras mínimas

\begin{tabular}{|c|c|c|c|c|c|}
\hline Armadura & Faixa & $\mathrm{H} 1 / \mathrm{H} 3$ & $\mathrm{H} 2$ & V1/V3 & V2 \\
\hline Positiva & MTA & 2,35 & 1,80 & 2,71 & 1,80 \\
\hline$\left(\mathrm{cm}^{2} / \mathrm{m}\right)$ & MTC & 2,35 & 1,80 & 1,80 & 1,80 \\
\hline Negativa & \multicolumn{3}{|c|}{$\begin{array}{l}\text { Nos apoios } \\
\text { Fora dos apoios }\end{array}$} & \multicolumn{2}{|c|}{$\begin{array}{c}15,47 \\
2,42\end{array}$} \\
\hline
\end{tabular}

2.4.6 Armaduras para atendimento do ELU

Foi verificada a necessidade de armadura complementar utilizando o CTNM e o ATOPRO através da análise de tensões. Certos casos foram utilizados armaduras complementares e em outras não, para evitar diminuição da altura útil das armaduras.

\subsubsection{Análise de tensões}

Analisou-se as tensões em cada RPU. Vale lembrar que para protensão parcial, é necessário apenas verificar na combinação frequente de ações, e verificar no ato 
da protensão o estado limite de fissuração. Foi calculada a necessidade de armadura complementar para cada RPU. Os cálculos foram executados levando em conta todas as premissas apresentadas até o momento.

\subsubsection{Detalhamento da armadura passiva}

Esta seção apresentará de forma gráfica todas as armaduras passivas calculadas. Notar que foram destacados em tracejado e preenchimento cinza as regiões consideradas para cálculo.

Da Figura 20 até a Figura 25 encontram-se estes desenhos de armaduras. Seus títulos se referem ao método utilizado para cálculo, a posição e direção das armaduras. Quando o método é suprimido, entende-se que o cálculo destas armaduras independe do método utilizado, estas situações ocorrem para a direção horizontal, a qual foi escolhida como região de cabos distribuída.

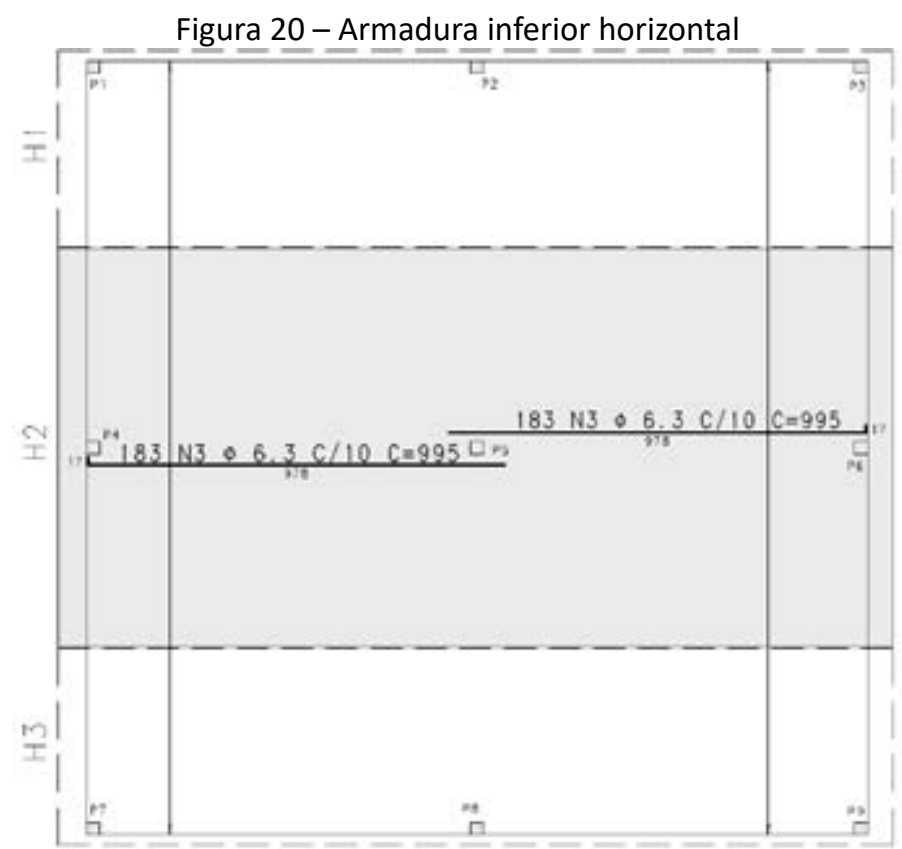

Fonte: Próprio autor, 2016

Figura 21 - Armadura superior horizontal 


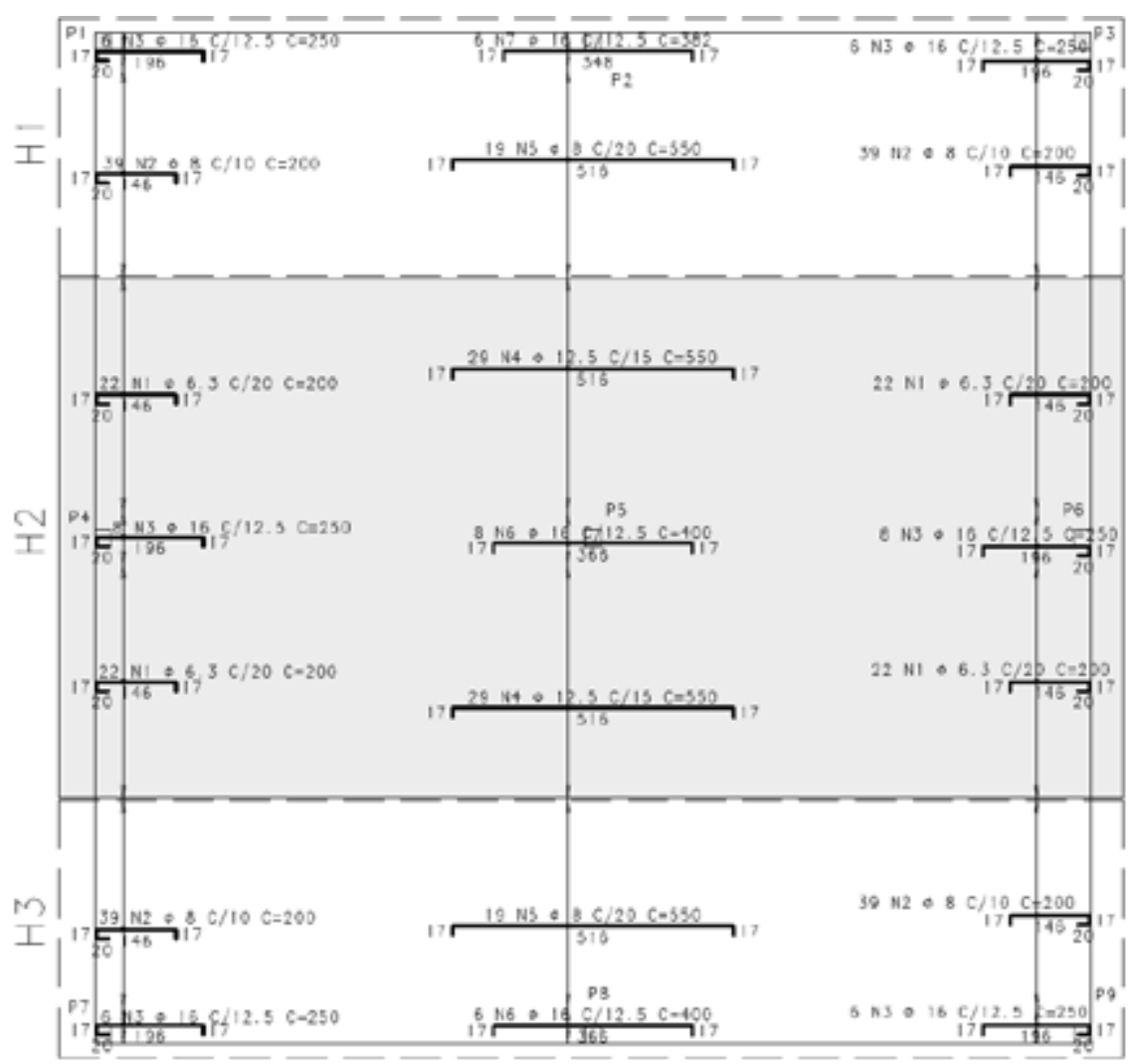

Fonte: Próprio autor, 2016 
Figura 22 - Armadura inferior vertical - MTA

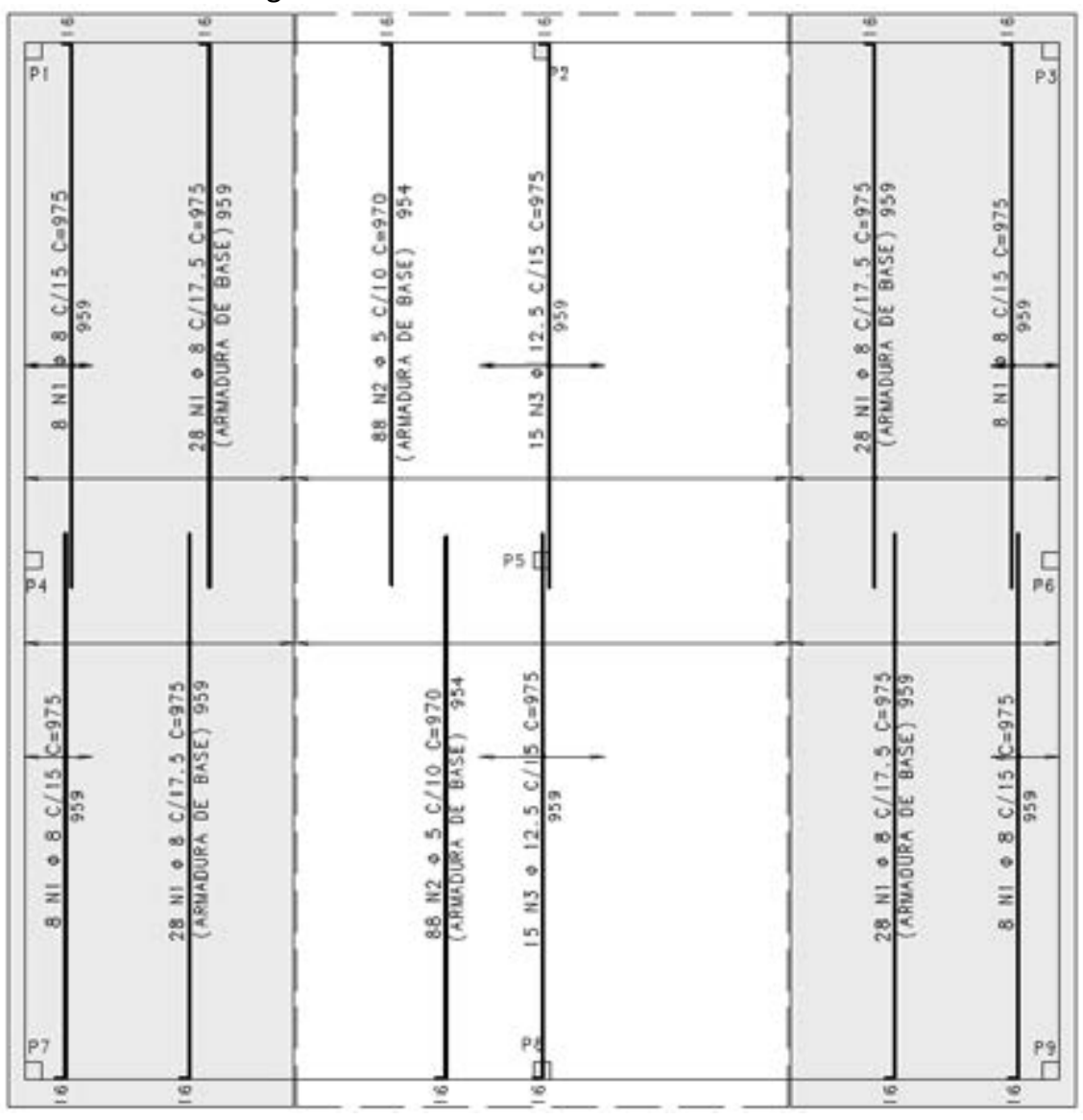

Fonte: Próprio autor, 2016 
Figura 23 - Armadura superior vertical - MTA

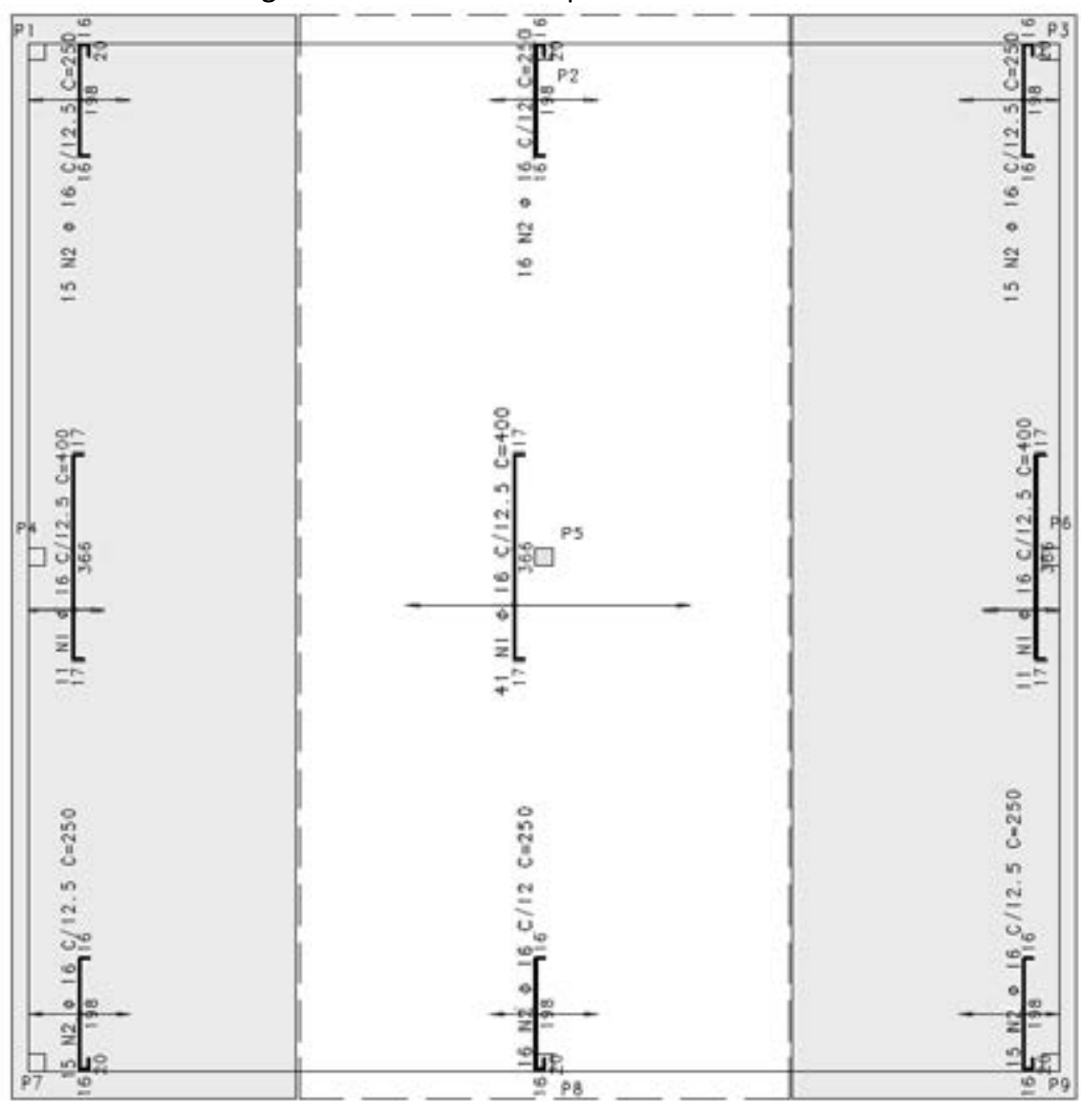

Fonte: Próprio autor, 2016 
Figura 24 - Armadura inferior vertical - MTC

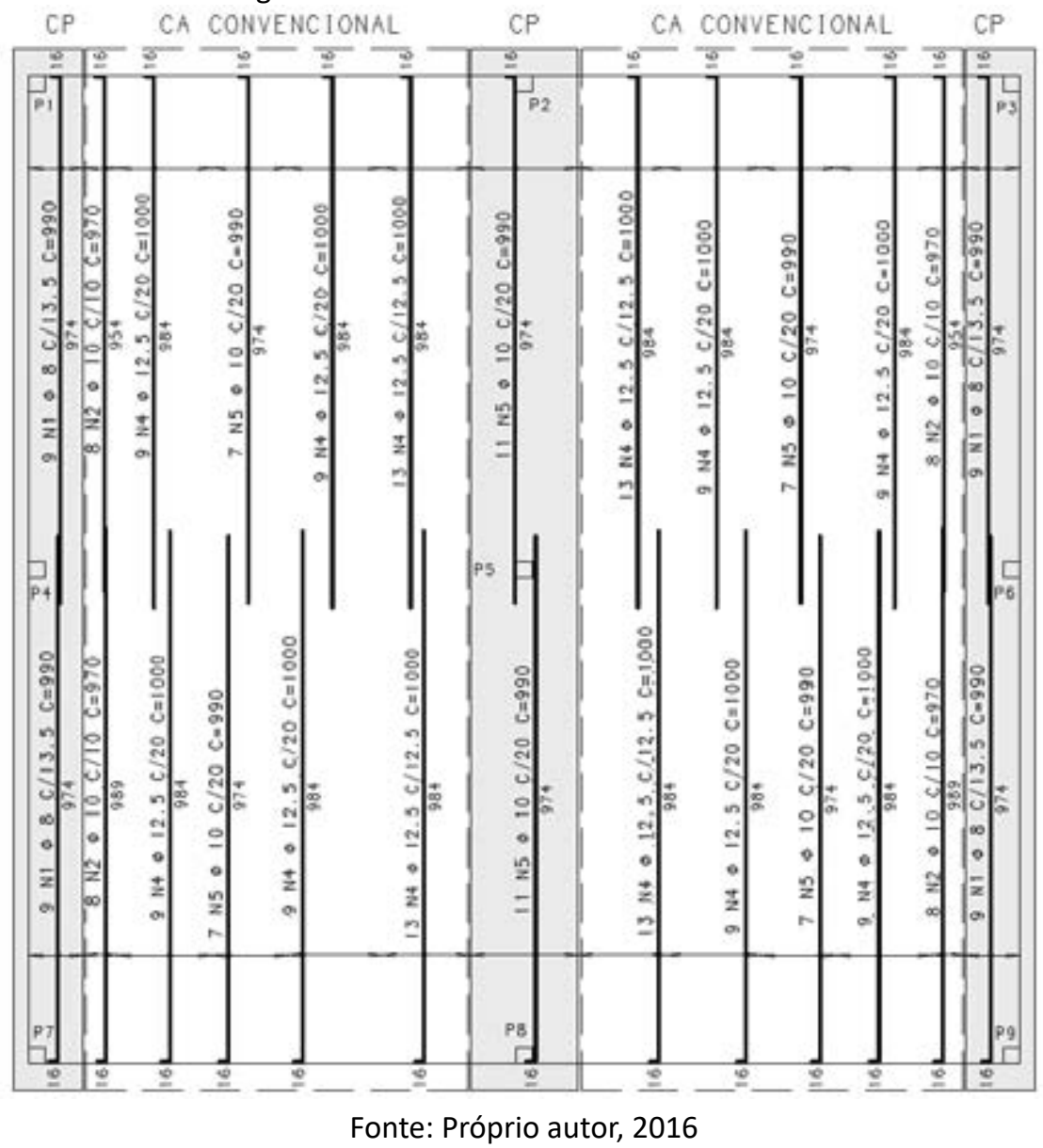


Figura 25 - Armadura superior vertical - MTC

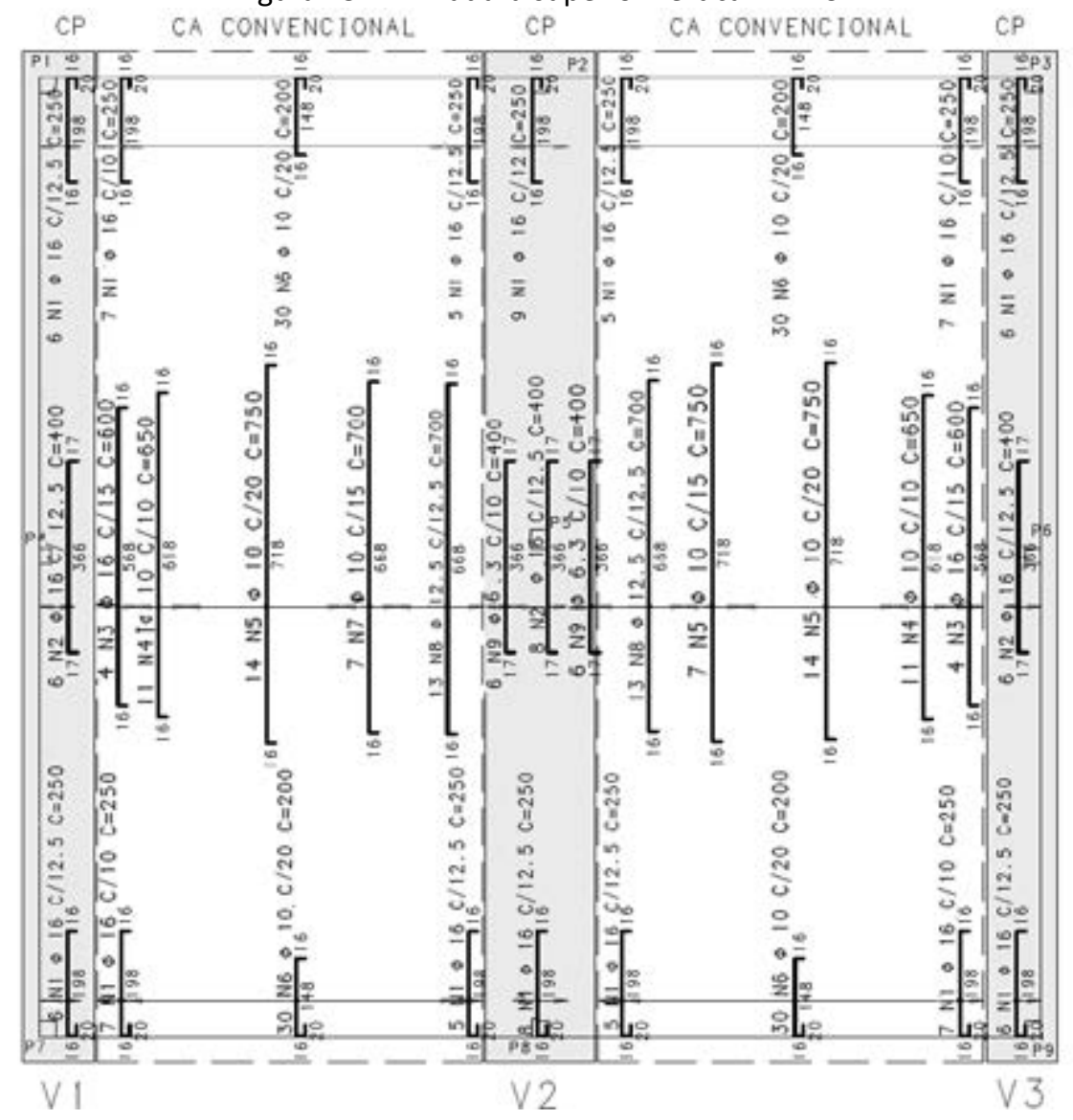

Fonte: Próprio autor, 2016

\subsubsection{Comparações}

A Tabela 2, demonstra os quantitativos das armaduras. Conforme já discutido, as armaduras horizontais são as mesmas para ambos os modelos, pois utilizando método das cargas equivalentes, essa direção não terá diferença no seu detalhamento, sabendo que para ambos os métodos, MTC e MTA, as faixas de projeto são idênticas.

Tabela 2 - Quantitativos

\begin{tabular}{|c|c|c|c|c|c|c|}
\hline \multirow{3}{*}{ Estrutura } & \multicolumn{6}{|c|}{ Armadura (kg) } \\
\hline & \multicolumn{2}{|c|}{ Positiva } & \multicolumn{2}{|c|}{ Negativa } & \multirow{2}{*}{ Ativa } & \multirow{2}{*}{$\begin{array}{c}\text { Total de Armadura } \\
\text { passiva }\end{array}$} \\
\hline & Horizontal & Vertical & Horizontal & Vertical & & \\
\hline MTC & 892 & 1827 & 838 & 1169 & 2035 & 4726 \\
\hline MTA & 892 & 1099 & 838 & 761 & 2035 & 3590 \\
\hline
\end{tabular}


O MTC apresentou um consumo 31,6\% maior que o MTA. Uma diferença desta escala é relevante o suficiente para justificar um maior empenho na seleção do método escolhido.

\section{CONSIDERAÇÕES FINAIS}

Avaliou-se nas verificações últimas situações onde a protensão não era suficiente para resistir aos esforços, sendo necessário uma complementação com armadura passiva. Com relação a isto, foram expostos dois métodos de seleção de faixas de projeto e discutiu-se o quanto estas influenciam no dimensionamento. Existem diversas particularidades estruturais que não permitem o uso de um método mais arrojado como o MTA, no entanto, o engenheiro deve ter sensibilidade para perceber quando este método é viável ou não.

Para estudo de caso foi dado enfoque as seleções de faixa de projeto abordando os dois métodos. Ao compará-los ficou explicitado, ao fim do detalhamento, que o MTC apresenta um consumo, de cerca de 32\%, maior de armadura passiva. Uma diferença desta magnitude pode inviabilizar projetos e demonstra que este assunto é de suma importância.

Apesar de existirem parâmetros para a seleção de faixas de projeto, estes não possuem limites bem definidos. Nota-se neste ponto uma lacuna no conhecimento, logo, tratar com mais profundidade e discutir acerca deste tema é uma sugestão para projetos futuros. Este estudo procura incentivar a discursão acadêmica ao mostrar a influência no quantitativo na escolha das faixas de projeto e expor os parâmetros de escolha de método de pouca precisão.

Cabe destacar que as armaduras mínimas negativas sobre os pilares são mais bem alinhadas, se for verificada uma comparação com o ELU, com o MTA. Este problema pode ter grande influência no quantitativo geral. Por isso indica-se também um estudo mais aprofundado quanto aos parâmetros para armadura mínima negativa, verificando o valor exigido por norma em situações diversas.

Observa-se como importante a execução desta mesma análise em estruturas reais onde questões como alinhamento de pilares e representatividade constante da seção da faixa de projeto não são bem definidas para testar os dois métodos. Uma verificação mais precisa seria possível em modelos reduzidos das estruturas.

$E$, finalmente, sugere-se que a partir da obtenção de dados por observação e 
instrumentação, em estruturas reais que possuam as configurações indicadas no corpo deste trabalho, e que através do projeto estrutural, compare-se o comportamento real e matemático obtido previamente. $\mathrm{O}$ acumulo de dados como estes é fundamental para afinar os modelos matemáticos atuais e futuros.

\section{REFERÊNCIAS}

ASSOCIAÇÃO BRASILEIRA DE NORMAS TÉCNICAS. NBR 6118: Projeto de Estruturas de Concreto: Procedimento. Rio de Janeiro, 2014.

AMERICAN CONCRETE INSTITUTE. ACI 318-08: Building Code Requirements for Structural Concrete and Commentary. Farmington Hills, 2008.

TQS INFORMÁTICA LTDA. TQS Pleno_LP\&S: V18. São Paulo, 2016.

LIN, Tung-Yen. LOAD-BALANCING METHOD FOR DESIGN AND ANALYSIS OF PRESTRESSED CONCRETE STRUCTURES. ACI Journal, Proceedings V.60, No. 6, junho de 1963, p. 719-742.

EMÉRICK, Alexandre José. PROJETO E EXECUÇÃO DE LAJES PROTENDIDAS. Rio de Janeiro: Editora Interciência. 2005

FARIA, Elves Lincoln. PROJETO DE LAJES PROTENDIDAS VIA MÉTODO DOS ELEMENTOS FINITOS E PÓRTICOS EQUIVALENTES. Belo Horizonte: UFMG-Escola de Engenharia, 2004.

LOUREIRO, Giordano José. PROJETO DE LAJES PROTENDIDAS COM CORDOALHAS ENGRAXADAS. São Paulo: EPUSP - Escola Politécnica da Universidade de São Paulo, 2006. 
SGARBI, Maurico. Projeto de Lajes Protendidas em Edifícios. Rio de Janeiro: ABECE. 2015.

TIMOSHENKO, S.; WOINOWSKY, K. THEORY OF PLATES AND SHELLS. New York: McGraw Hill, 1959. 